\title{
Altered Expression of $\beta$-Catenin without Genetic Mutation in Intrahepatic Cholangiocarcinoma
}

\author{
Keishi Sugimachi, M.D., Ken-ichi Taguchi, M.D., Shin-ichi Aishima, M.D., Shinji Tanaka, M.D., Ph.D., \\ Mitsuo Shimada, M.D., Ph.D., Kiyoshi Kajiyama, M.D., Ph.D., Keizo Sugimachi, M.D., Ph.D., FACS, \\ Masazumi Tsuneyoshi, M.D., Ph.D. \\ Department of Anatomic Pathology (KS, KT, SA, MT) and Department of Surgery and Science (ST, MS, KK, \\ KS) Graduate School of Medical Sciences, Kyushu University, Fukuoka, Japan
}

$\beta$-catenin which has a role in E-cadherin mediated cell-to-cell adhesion, and is also involved in Wnt signaling pathways as a downstream signaling molecule accumulating in the cytoplasm and nucleus constitutively activates Tcf/LEF-associated transcription of oncogenic genes. We examined the expression pattern and the genetic alteration of $\beta$-catenin to determine the role of $\beta$-catenin in cancer formation and/or progression in intrahepatic cholangiocarcinoma (ICC). $\beta$-catenin expression was immunohistochemically examined in 71 surgically resected ICC samples, and correlation between the expression pattern and clinicopathologic factors was investigated. Mutation analysis of $\beta$-catenin exon 3, which included the responsible element for Wnt signaling was done in 55 samples, using PCRSSCP and direct sequence methods. Immunohistochemical analysis revealed the reduced membranous expression of $\beta$-catenin in $58(82 \%)$ ICCs and aberrant nuclear expression in 11 (15\%) ICCs. The membranous expression was preserved in $62 \%$ of the papillary adenocarcinomas, and was frequently reduced in tumors with a poorer histological differentiation $(84 \%)$, with a significant difference $(P=$ $.01)$. Genetic analysis showed that none of the 55 ICCs examined carried mutations in $\beta$-catenin exon 3. The present study indicates that reduced membranous expression of $\beta$-catenin is associated with non-papillary ICCs which have a more malignant behavior, and that nuclear translocation of $\beta$-catenin results in oncogenic events. Mutations in $\beta$-catenin exon 3 do not appear to be responsible for nuclear translocation of $\beta$-catenin in ICCs.

Copyright () 2001 by The United States and Canadian Academy of Pathology, Inc.

VOL. 14, NO. 9, P. 900, 2001 Printed in the U.S.A.

Date of acceptance: May 10, 2001.

Address reprint requests to: Masazumi Tsuneyoshi M.D., Ph.D., Department of Anatomic Pathology, Graduate School of Medical Sciences, Kyushu University, 3-1-1 Maidashi, Higashi-ku, Fukuoka 812-8582, Japan; e-mail: masazumi@surgpath.med.kyushu-u.ac.jp; Fax: +81-92-642-5968.
KEY WORDS: Intrahepatic cholangiocarcinoma (ICC), $\beta$-catenin, Cell-to-cell adhesion, Nuclear translocation, Immunohistochemistry, PCR-SSCP, Direct sequence.

Mod Pathol 2001;14(9):900-905

Intrahepatic cholangiocarcinoma (ICC) is the second most common primary malignant liver tumor after to hepatocellular carcinoma (HCC) in Japan (1). Despite diagnostic and therapeutic procedures such as surgical resection, which is the first choice of treatment, and various adjuvant therapies, the prognosis of ICC remains poor $(1,2)$. Knowledge of the molecular mechanisms involved in ICC is important as it may contribute to a better understanding of the carcinogenesis of ICC and effective therapy for ICC patients may ensue.

$\beta$-catenin is a dual functional protein, which acts as a key structural molecule in E-cadherin mediated cell-to-cell adhesion, and also plays an important role in Wnt signaling pathways (3). $\beta$-catenin, a 95-kd protein, was initially identified as the undercoat protein of E-cadherin, which strengthens the linkage of E-cadherin and $\alpha$-catenin to the actin cytoskeleton (4). $\beta$-catenin is also a key functional protein in Wnt signaling pathways during embryonic development and tumorigenesis $(3,5)$. Wnt stimulation stabilizes cytoplasmic $\beta$-catenin, and thus enhances binding with the $\mathrm{T}$ cell factor/lymphoid enhancer factor (Tcf/Lef) family of transcription factors in the nucleus (6), which results in events activating expression of Tcf/Lef-regulated target genes such as c-myc, cyclin D1 and matrilysin (matrix metalloproteinase-7) (7-9). Thus, the function of $\beta$-catenin as an oncogene depends on its accumulation and subsequent translocation in the nucleus (3). The level of $\beta$-catenin is regulated by the phosphorylation of $\beta$-catenin by adenomatous polyposis coli (APC) tumor suppressor protein, axin and the glycogen synthase kinase $3 \beta$ (GSK-3 $\beta$ ) complex which leads to degradation of $\beta$-catenin by the ubiquitin-proteasome complex $(10,11)$. Thus, 
$\beta$-catenin can be oncogenically activated by direct genetic mutation of the phosphorylated site of $\beta$-catenin, by the inactivation of APC, axin or GSK $-3 \beta$ or by activation of Wnt signaling pathways (5).

Immunolocalization of $\beta$-catenin in the nucleus and genetic alteration of the phosphorylated site by GSK- $3 \beta$ in exon 3 of $\beta$-catenin was noted in human malignant tumors such as colorectal cancer, HCC, prostate cancer, melanoma, ovarian cancer and synovial sarcoma (12-18). In case of ICC, little is known of genetic alterations of molecules which contribute to activating Wnt signaling pathways. We immunohistochemically determined the localization of $\beta$-catenin, and screened for mutation of $\beta$-catenin exon 3 .

\section{MATERIALS AND METHODS}

\section{Patients}

The present study was based on data on 71 surgically resected ICCs of 67 Japanese patients, which included 67 primary cases and 4 recurrent cases. All these data were collected in the Department of Anatomic Pathology, Graduate School of Medicine, Kyushu University, Fukuoka, Japan from July, 1987 to June, 1999. There were 40 men and 27 women, and ages ranged from 33 to 79 years (mean 61.6 years). All tumors were defined as primary ICCs arising from intrahepatic bile ducts, and tumors arising from extrahepatic bile ducts were excluded from this study. Tumors were reviewed and classified histologically by three authors (K.S., K.T., and M.T.), based on the classification of the Japanese Society of Biliary Surgery $(2,19)$. There were 8 papillary adenocarcinomas, 11 well differentiated adenocarcinomas, 27 moderately differentiated adenocarcinomas, and 25 poorly differentiated adenocarcinomas. There was no patient with primary sclerosing cholangitis. The clinical follow-up period for all patients was $26.1 \pm 23.7$ months. During the follow-up period, 38 of the 67 patients $(56.7 \%)$ died of the disease.

\section{Immunohistochemical Staining of $\beta$-Catenin}

One representative section from formalin-fixed, paraffin-embedded tissue was processed for immunohistochemical staining. Endogenous peroxidase activity was blocked for 30 minutes, using methanol containing $0.3 \% \mathrm{H}_{2} \mathrm{O}_{2}$. Sections were heated in $\mathrm{pH}$ 6.0 citrate buffer at $100^{\circ} \mathrm{C}$ for 20 minutes in a microwave oven at 500 watts to retrieve the antigen. Non-specific antibody binding was blocked for 20 minutes by incubation with $10 \%$ normal rabbit serum.

Sections were incubated with primary monoclonal antibody against $\beta$-catenin (Transduction Lab- oratories, Lexington, KY; diluted 1:200) overnight at $4^{\circ} \mathrm{C}$. The primary antibody was visualized using a streptavidin-biotin-peroxidase kit (Nichirei, Tokyo, Japan) with diaminobenzidine tetrahydrochloride (3,3'-diaminobenzidine) as the chromogen. These sections were then lightly couterstained by hematoxylin. Positive immunoreactivity of normal bile duct epithelium was confirmed to be a positive control for each specimen (20). Phosphate-buffered saline instead of the primary antibody was used as the negative control.

\section{Evaluation of Immunohistochemical Staining}

The immunohistochemical expression pattern of $\beta$-catenin was categorized by two different methods; 1) membranous expression and 2) nuclear expression. The cell membranous staining of $\beta$-catenin was evaluated semiquantitatively, irrespective of the nuclear expression, and tumors were divided into two groups; 1) preserved membranous expression pattern: more than $75 \%$ of tumor cells showed equivalent membranous staining to adjacent normal bile duct epithelium, and others were considered to be 2) reduced membranous expression pattern, as described elsewhere $(17,18)$.

Nuclear expression was also categorized into two groups; 1$)$ nuclear pattern: $\beta$-catenin showed unequivocal nuclear staining in at least one area of the tumor, irrespective of the percentage of stained nuclei or simultaneous staining in cell membrane or cytoplasm, 2) membranous pattern: $\beta$-catenin stained only in the cell membrane.

\section{Polymerase Chain Reaction-Single Strand Conformation Polymorphism (PCR-SSCP) Analysis of $\beta$-Catenin Exon 3}

Genomic DNA was extracted and purified from 55 paraffin-embedded ICC samples, as described (18). PCR-SSCP analysis for $\beta$-catenin exon 3 was made using primers 471F (5'-AAAGCGGCTGTTAGTCACTGG-3') and 602R (5'-GACTTGGGAGGTATCCACATCC-3'), including coding for the GSK- $3 \beta$ phosphorylation consensus region of $\beta$-catenin which has been found to contain activating mutations $(15,18)$. The PCR mixture contained $1 \mu \mathrm{L}$ of template DNA (50 $\mathrm{ng} / \mu \mathrm{L}$ ), $2 \mu \mathrm{L}$ of $10 \times$ PCR buffer (Takara Shuzo, Shiga, Japan), $1.6 \mu \mathrm{L}$ of dNTP mixture (Takara Shuzo), 0.4 $\mu \mathrm{M}$ of each primer and $0.5 \mathrm{U}$ of TaKaRa Taq (Takara Shuzo) in a final volume of $20 \mu \mathrm{L}$. The reaction was run in a thermal cycler (GeneAmp ${ }^{\mathrm{TM}}$ PCR System 9600, Perkin-Elmer, Norfolk, CT), and the conditions were 4 minutes of initial denaturation at $94^{\circ} \mathrm{C}$ and 40 cycles consisting of 1 minute of denaturation at $94^{\circ} \mathrm{C}$, annealing at $53^{\circ} \mathrm{C}$ and extension at $72^{\circ} \mathrm{C}$, followed by 4 minutes of final extension step at $72^{\circ} \mathrm{C}$. The PCR products were diluted 1:1 in loading buffer ( $94 \%$ for- 
mamide, $10 \mathrm{mg}$ bromphenol blue, $0.05 \%$ xylene cyanol), heated at $95^{\circ} \mathrm{C}$ for 5 minutes and snap frozen on ice. Then, the samples were electrophoresed onto a $12.5 \%$ acrylamide gel (GenePhor ${ }^{\mathrm{TM}}$, Amersham Pharmatica Biotech, Sweden) at $5^{\circ} \mathrm{C}$ and visualized using a DNA Silver Staining Kit (GenePhor ${ }^{\mathrm{TM}}$ ). Human genomic DNA (CLONTECH, Palo Alto, CA) was used as a negative control in order to evaluate the mobility shifted bands of SSCP.

\section{Direct Sequence Analysis of $\beta$-Catenin Exon 3}

Genomic DNA was extracted and purified from 21 fresh frozen ICC samples, using standard proteinase K digestion and phenol/chloroform extraction. PCR analysis for $\beta$-catenin exon 3 was done using primers 393F (5'-CCAATCTACTAATGCTAATACTG-3') and 746R (5'-TACTCTCTTTTCTTCACCACAAC-3'), which contain the entire coding region of $\beta$-catenin exon 3 , including the GSK- $3 \beta$ phosphorylation consensus region. PCR conditions were 35 cycles consisting of 1 minute denaturation at $94^{\circ} \mathrm{C}$, annealing at $50^{\circ} \mathrm{C}$ and extension at $72^{\circ} \mathrm{C} .5 \mu \mathrm{l}$ of the purified PCR products was used in a thermocycle sequencing reaction with the Dye Terminator Cycle Sequence FS Ready Reaction Kit (Applied Biosystems, Foster City, CA), and polyacrylamide gel electrophoresis was done using standard conditions on a ABI Prism 310 fluorescencebased, semi-automated DNA sequencer (PerkinElmer) in accord with the manufacturer's instructions. For all sequence reactions we used both the forward and reverse primers for each of the $\beta$-catenin regions.

\section{Statistical Analysis}

Comparisons between $\beta$-catenin expression patterns and clinicopathologic parameters were evaluated using chi-square test. The significance of parameters on survival was analyzed by the KaplanMeier method and their differences with log-rank test. A $P$ value of less than 0.05 was considered to be statistically significant.

\section{RESULTS}

Immunohistochemical Expression of $\beta$-Catenin and Comparison with Clinicopathological

\section{Variables}

The relationship between $\beta$-catenin expression pattern and clinicopathological features is summarized in Table 1. While membranous expression of $\beta$-catenin was preserved in all of the adjacent normal bile duct epithelium, only thirteen $(18 \%)$ of the 71 ICCs had a preserved membranous expression pattern (Fig. 1). The remaining 58 (82\%) tumors had a reduced membranous expression pattern (Fig. 2), and the expression pattern correlated well with his-
TABLE 1. Comparison of Clinicopathological Variables between Preserved and Reduced Membranous Expression Patterns of $\boldsymbol{\beta}$-Catenin

\begin{tabular}{lccc}
\hline \multicolumn{1}{c}{ Variables } & $\begin{array}{c}\text { Reduced } \\
\text { Pattern } \\
(n=58)\end{array}$ & $\begin{array}{c}\text { Preserved } \\
\text { Pattern } \\
(n=13)\end{array}$ & P-value \\
\hline Sex (male:female) & $34: 24$ & $9: 4$ & NS \\
Age (years) & $62.4 \pm 10.7$ & $58.1 \pm 8.0$ & NS \\
Tumor size (cm) & $4.6 \pm 2.2$ & $4.6 \pm 2.6$ & NS \\
Histological type & $3(38)$ & $5(62)$ & .01 \\
PA $(n=8)$ & $10(91)$ & $1(9)$ & \\
WDA $(n=11)$ & $23(85)$ & $4(15)$ & \\
MDA $(n=27)$ & $22(88)$ & $3(12)$ & NS \\
$\quad$ PDA $(n=25)$ & $12(21)$ & $1(8)$ & NS \\
Scirrhous fashion & $35(43)$ & $9(69)$ & NS \\
$\quad$ Scirrhous type & $33(21)$ & $7(54)$ & NS \\
Vascular invasion $(+)$ & $34(44)$ & $7(54)$ & NS \\
Lymphatic permeation $(+)$ & $22(48)$ & $3(23)$ & \\
Perineural invasion $(+)$ & & & \\
Lymph node metastases $(+)$ & &
\end{tabular}

PA, papillary adenocarcinoma; WDA, well differentiated adenocarcinoma; MDA, moderately differentiated adenocarcinoma; PDA, poorly differentiated adenocarcinoma; NS, not significant.

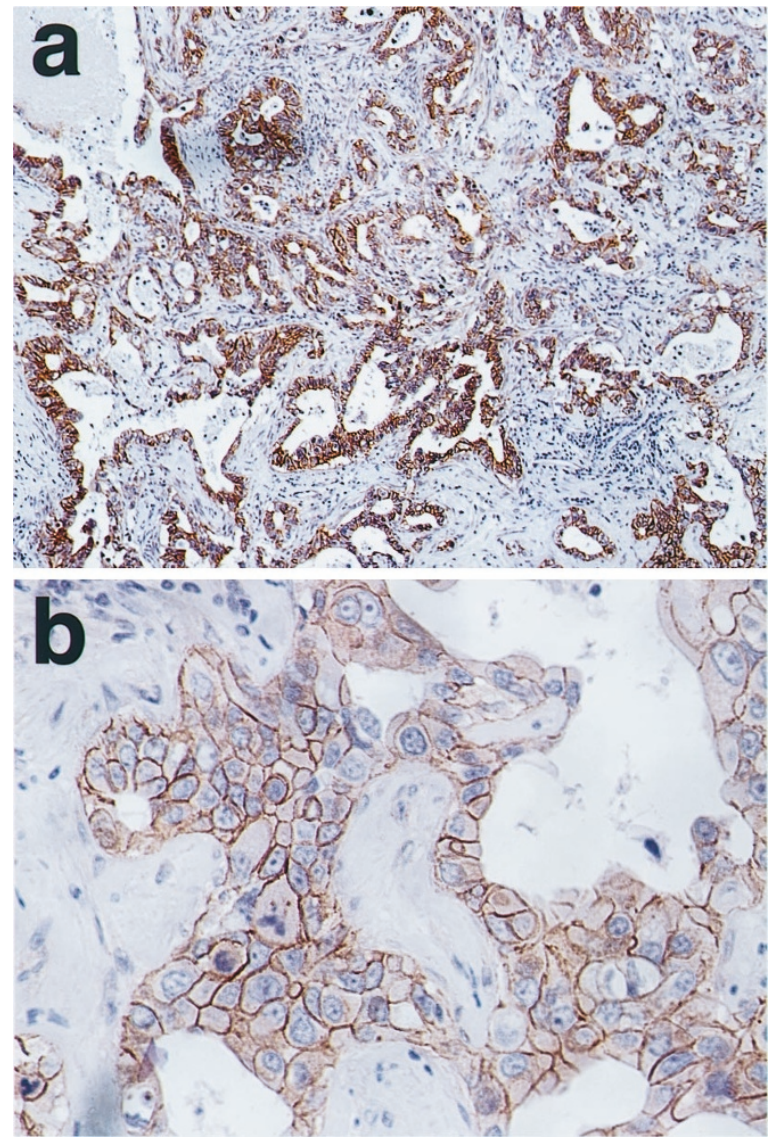

FIGURE 1. Preserved membranous expression pattern of $\beta$-catenin Carcinoma cells showed diffuse strong cell membranous expression (original magnification: A, $40 \times$; B, $400 \times$ ).

tological type of the tumor. Twenty-two of the 25 poorly differentiated type (88\%), 23 of the 27 moderately differentiated type $(85 \%)$ and 10 of the 11 well differentiated type $(91 \%)$ showed a reduced membranous expression pattern, while only 3 of the 8 papillary type $(38 \%)$ had the preserved mem- 

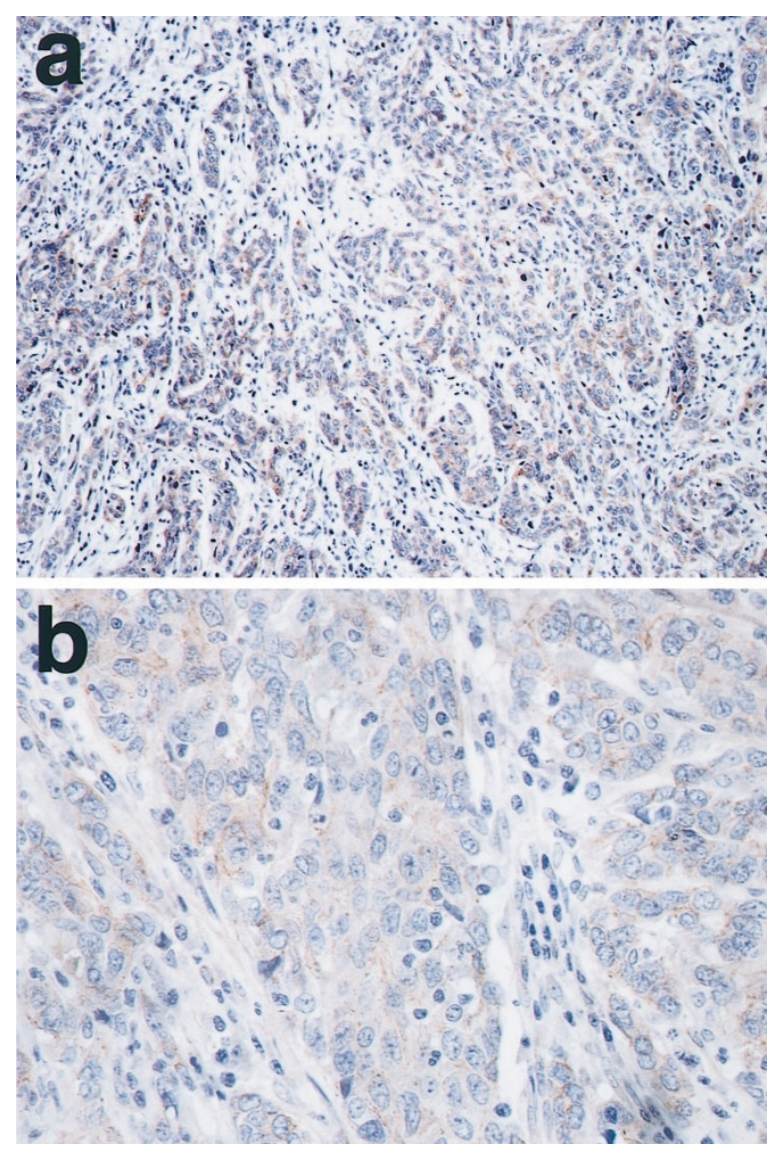

FIGURE 2. Reduced membranous expression pattern of $\beta$-catenin. Carcinoma cells showed weak cell membranous expression (original magnification: A, $40 \times$; B, $400 \times$ ).

branous expression pattern, with a significant difference $(P=.01)$.

Nuclear $\beta$-catenin expression was observed in 11 (15\%) of 71 ICCs, but not in any of the normal bile duct epithelium (nuclear pattern, Fig. 3). Eight of these 11 tumors $(73 \%)$ had a reduced membranous expression. Of the 13 tumors which had a preserved membranous expression of $\beta$-catenin, 3 (23\%) had a nuclear expression of $\beta$-catenin. All of these 3 tumors were the undifferentiated type (1 poorly and 2 moderately differentiated type). Nuclear accumulation of $\beta$-catenin seemed to more likely occur in the undifferentiated type ICCs with a preserved membranous expression. The expression pattern (nuclear or membranous pattern), however, did not correlate statistically with clinicopathological features (Table 2), including scirrhous fashion (3) and the overall survival rate (data not shown).

\section{Mutation Analysis of $\beta$-Catenin Exon 3}

A portion of exon 3 coding for the GSK- $3 \beta$ phosphorylation consensus region of $\beta$-catenin from 55 ICCs was screened by PCR-SSCP (18), and the entire coding region of $\beta$-catenin exon 3 was analyzed by

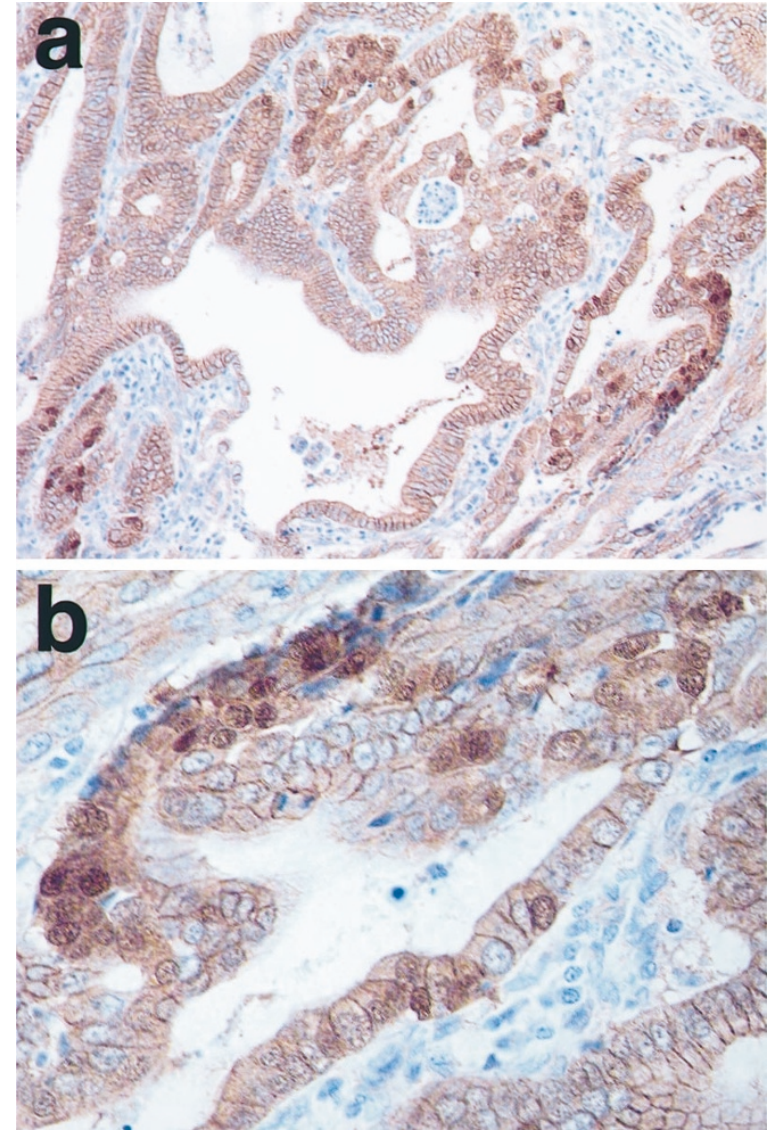

FIGURE 3. Nuclear expression pattern of $\beta$-catenin. Strong nuclear staining of $\beta$-catenin was observed in well differentiated adenocarcinoma cells (original magnification: A, 100×; B, 400×).

TABLE 2. Comparison of Clinicopathological Variables between Nuclear and Membranous Expression Patterns of $\beta$-Catenin

\begin{tabular}{llcc}
\hline \multicolumn{1}{c}{ Variables } & $\begin{array}{c}\text { Nuclear } \\
\text { Pattern } \\
(n=11)\end{array}$ & $\begin{array}{c}\text { Membranous } \\
\text { Pattern } \\
(n=60)\end{array}$ & P-value \\
\hline Histological type & & & NS \\
PA (n = 8) & $1(13)$ & $7(87)$ & \\
WDA (n = 11) & $1(9)$ & $10(91)$ & \\
MDA (n = 27) & $5(19)$ & $22(81)$ & \\
PDA (n = 25) & $4(16)$ & $21(84)$ & NS \\
Scirrhous fashion & & & \\
Scirrhous type & $1(9)$ & $9(15)$ & NS \\
Vascular invasion $(+)$ & $8(73)$ & $36(60)$ & NS \\
Lymph node metastases $(+)$ & $4(36)$ & $21(35)$ & \\
\hline
\end{tabular}

PA, papillary adenocarcinoma; WDA, well differentiated adenocarcinoma; MDA, moderately differentiated adenocarcinoma; PDA, poorly differentiated adenocarcinoma; NS, not significant.

direct sequencing in 21 ICCs. The series of 55 tumors analyzed contained 10 tumors immunohistochemically identified as nuclear expression pattern of $\beta$-catenin. A representative of the gel patterns of PCR-SSCP and results of direct sequence analysis are shown in Figure 4. Aberrant mobility shift and genetic mutations were never detected in any of our samples. 


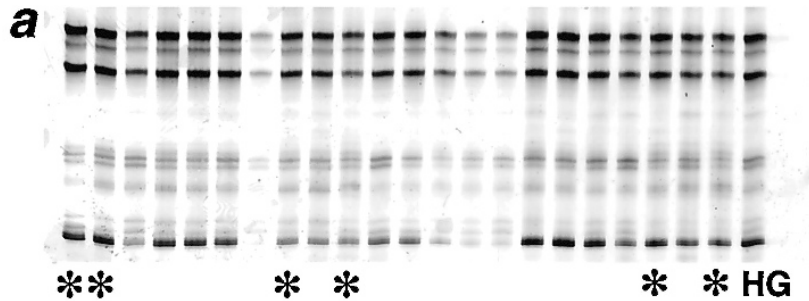

b

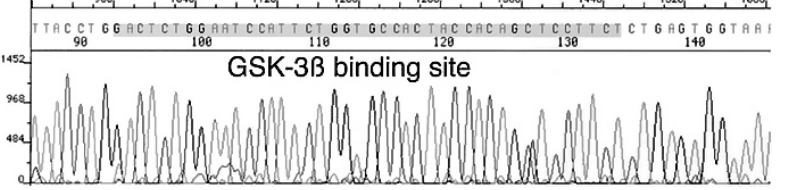

FIGURE 4. A, PCR-SSCP of the $\beta$-catenin exon 3 . There was no mobility shifted band compared to human genomic DNA (HG). *Cases of nuclear accumulation of $\beta$-catenin determined by

immunohistochemistry. B, Representative figure of direct sequence analysis of $\beta$-catenin exon 3 in case of nuclear accumulation of $\beta$ catenin, determined using immunohistochemistry. GSK- $3 \beta$ binding site of $\beta$-catenin exon 3 showed no abnormalities.

\section{DISCUSSION}

The aberrant nuclear translocation of $\beta$-catenin activates the transcription of target genes such as c-myc, cyclin D1 and MMP-7 (7-9), and thus may contribute to carcinogenesis $(5,21)$. This can be a consequence of genetic alteration of $\beta$-catenin itself or of other molecules in the Wnt signaling pathway $(5,22-24)$. We evaluated the cellular localization of $\beta$-catenin from two different points of view; membranous and nuclear expression pattern, since these patterns reflect the dual function of $\beta$-catenin which involves both cadherin mediated cell-to-cell adhesion and Wnt signaling pathways. We observed a reduced membranous expression of $\beta$-catenin in $82 \%$ of the ICCs examined. Reduced membranous expression of $\beta$-catenin has been noted in various human malignant tumors (25). In the current study, the membranous expression of $\beta$-catenin was well preserved in papillary adenocarcinoma, which showed characteristic intraductal growth with a lesser degree of invasiveness and a favorable prognosis (26), compared with the other invasive type of ICC, with a significant difference $(P=.01)$, These results support the data of Ashida et al. who described a reduced membranous expression of $\beta$-catenin and histological differentiation of ICC (20). Our observations suggest that reduction of membranous $\beta$-catenin leads to loss of a cell-to-cell adhesion, an event which may contribute to the invasive tendency of ICC (27).

$\beta$-catenin could be involved in cancer formation and/or progression if it translocates into the nucleus and activates transcription of target genes with Tcf/Lef family transcription factors $(5,6)$. We immunohistochemically detected strong nuclear accumulation of $\beta$-catenin in $15 \%$ of the ICCs we studied herein, while none of the non-cancerous bile duct epithelium showed nuclear expression. Our data indicate that the nuclear translocated $\beta$-catenin, the result of an activated $\mathrm{Wnt} / \beta$-catenin/Tcf pathway, plays a significant role in cholangiocarcinogenesis, and is independent of adhesive related functions. Consistent with these findings, our studies provide strong evidence for the biological significance of an activated $\beta$-catenin pathway in ICC.

Aberrant nuclear expression was induced by the increased stabilization of $\beta$-catenin protein $(3,5)$. Recently, mutations of $\beta$-catenin exon 3 containing the GSK- $3 \beta$ phosphorylated site, associated with nuclear translocation, have been noted in human malignant tumors (5). Such genetic changes contribute to oncogenical functions of $\beta$-catenin. In the present study, abnormalities of the $\beta$-catenin exon 3 gene were not detected in a series of 55 ICCs, using PCR-SSCP and direct sequence analysis. The manner in which $\beta$-catenin is translocated into the nucleus in cholangiocarcinoma cells is not clear, and events other than mutations of $\beta$-catenin may be responsible. In colorectal cancer, deletion of APC as well as mutation of $\beta$-catenin seems important to activate $\beta$-catenin (23). It was reported that there is genetic alteration of molecules such as Wnt (28, 29), Wnt receptor (22) and axin (24) which activate the $\beta$-catenin pathway in human cancers. In ICC, Kang et al. reported the loss of heterozygosity of APC gene in ICCs (30), but deletion or mutation of APC was not discussed.

In summary, reduced membranous expression and nuclear translocation of $\beta$-catenin are involved in cholangiocarcinogenesis, progression and invasion, and blocking this pathway (22) may lead to appropriate therapy for patients with ICC.

Acknowledgments: We thank the staff in the Department of Surgery and Science of Kyushu University, and affiliated hospitals (Fukuoka City Hospital, Iizuka Hospital, National Oita Hospital, Munakata Ishikai Hospital, Fukuoka Saiseikai Hospital and Kyushu Central Hospital) for providing tissue samples. We also thank M. Ohara for helpful comments on the manuscript and Y. Nozuka and M. Hirata for excellent technical assistance.

\section{REFERENCES}

1. Primary liver cancer in Japan. Clinicopathologic features and results of surgical treatment. Liver Cancer Study Group of Japan. Ann Surg 1990; 211: 277-87.

2. Kajiyama K, Maeda T, Takenaka K, Sugimachi K, Tsuneyoshi M. The significance of stromal desmoplasia in intrahepatic cholangiocarcinoma: a special reference of "scirrhous-type" and "nonscirrhous-type" growth. Am J Surg Pathol 1999;23: 892-902. 
3. Bullions LC, Levine AJ. The role of beta-catenin in cell adhesion, signal transduction, and cancer. Review Curr Opin Oncol. 1998;10:81-7.

4. Aberle H, Schwartz H, Kemler R. Cadherin-catenin complex: protein interactions and their implications for cadherin function [review]. J Cell Biochem 1996 Jun;61:514-23.

5. Polakis P. The oncogenic activation of beta-catenin [review]. Curr Opin Genet Dev 1999;9:15-21.

6. Behrens J, von Kries JP, Kuhl M, Bruhn L, Wedlich D, Grosschedl $\mathrm{R}$, et al. Functional interaction of beta-catenin with the transcription factor LEF-1. Nature 1996;382:638-42.

7. He TC, Sparks AB, Rago C, Hermeking H, Zawel L, da Costa LT, et al. Identification of c-MYC as a target of the APC pathway. Science 1998;281:1509-12.

8. Tetsu O, McCormick F. Beta-catenin regulates expression of cyclin D1 in colon carcinoma cells. Nature 1999;398:422-6.

9. Crawford HC, Fingleton BM, Rudolph-Owen LA, Goss KJ, Rubinfeld B, Polakis P, et al. The metalloproteinase matrilysin is a target of beta-catenin transactivation in intestinal tumours. Oncogene 1999;18:2883-91.

10. Aberle H, Bauer A, Stappert J, Kispert A, Kemler R. Betacatenin is a target for the ubiquitin-proteasome pathway. EMBO J 1997;16:3797-804.

11. Rubinfeld B, Albert I, Porfiri E, Fiol C, Munemitsu S, Polakis P. Binding of GSK3beta to the APC-beta-catenin complex and regulation of complex assembly. Science 1996;272:1023-6.

12. Sparks AB, Morin PJ, Vogelstein B, Kinzler KW. Mutational analysis of the APC/ $\beta$-catenin/Tcf pathway in colorectal cancer. Cancer Res 1998;58:1130-4.

13. de La Coste A, Romagnolo B, Billuart P, Renard CA, Buendia MA, Soubrane O, et al. Somatic mutations of the $\beta$-catenin gene are frequent in mouse and human hepatocellular carcinomas. Proc Natl Acad Sci USA 1998;95:8847-51.

14. Miyoshi Y, Iwao K, Nagasawa Y, Aihara T, Sasaki Y, Imaoka S, et al. Activation of the $\beta$-catenin gene in primary hepatocellular carcinomas by somatic alterations involving exon 3 . Cancer Res 1998;58:2524-7.

15. Voeller HJ, Truica CI, Gelmann EP. $\beta$-catenin mutations in human prostate cancer. Cancer Res 1998;58:2520-3.

16. Rimm DL, Caca K, Hu G, Harrison FB, Fearon ER. Frequent nuclear/cytoplasmic localization of $\beta$-catenin without exon 3 mutations in malignant melanoma. Am J Pathol 1999;154: 325-9.

17. Gamallo C, Palacios J, Moreno G, Calvo de Mora J, Suarez A, Armas A. Beta-catenin expression pattern in stage I and II ovarian carcinomas: relationship with beta-catenin gene mutations, clinicopathological features, and clinical outcome. Am J Pathol 1999;155:527-36.
18. Saito T, Oda Y, Sakamoto A, Tamiya S, Kinukawa N, Hayashi $\mathrm{K}$, et al. Prognostic value of the preserved expression of the E-cadherin and catenin families of adhesion molecules and of beta-catenin mutations in synovial sarcoma. J Pathol 2000;192:342-50.

19. Japanese Society of Biliary Surgery (JSBS). General rules for surgical and pathological studies on cancer of the biliary tract. 4th ed. Tokyo: Kanehara Publications, 1997.

20. Ashida K, Terada T, Kitamura Y, Kaibara N. Expression of E-cadherin, alpha-catenin, beta-catenin, and CD44 (standard and variant isoforms) in human cholangiocarcinoma: an immunohistochemical study. Hepatology 1998;27:97482.

21. Lin SY, Xia W, Wang JC, Kwong KY, Spohn B, Wen Y, et al. $\beta$ -Catenin, a novel prognostic marker for breast cancer: its roles in cyclin D1 expression and cancer progression. Proc Natl Acad Sci USA 2000;97:4262-6.

22. Tanaka S, Akiyoshi T, Mori M, Wands JR, Sugimachi K. A novel frizzled gene identified in human esophageal carcinoma mediates APC/beta-catenin signals. Proc Natl Acad Sci USA 1998;95:10164-9.

23. Morin PJ, Sparks AB, Korinek V, Barker N, Clevers H, Vogelstein $\mathrm{B}$, et al. Activation of beta-catenin-Tcf signaling in colon cancer by mutations in beta-catenin or APC. Science 1997;275:1787-90.

24. Satoh S, Daigo Y, Furukawa Y, Kato T, Miwa N, Nishiwaki T, et al. AXIN1 mutations in hepatocellular carcinomas, and growth suppression in cancer cells by virus-mediated transfer of AXIN1. Nat Genet 2000;24:245-50.

25. Hirohashi S. Inactivation of the E-cadherin-mediated cell adhesion system in human cancers [review] Am J Pathol 1998;153:333-9.

26. Shibata T, Ochiai A, Kanai Y, Akimoto S, Gotoh M, Yasui N, et al. Dominant negative inhibition of the association between $\beta$-catenin and c-erbB- 2 by $N$-terminally deleted $\beta$-catenin suppresses the invasion and metastasis of cancer cells. Oncogene 1996;13:883-9.

27. Suh KS, Roh HR, Koh YT, Lee KU, Park YH, Kim SW. Clinicopathologic features of the intraductal growth type of peripheral cholangiocarcinoma. Hepatology 2000;31:12-7.

28. Vider BZ, Zimber A, Chastre E, Prevot S, Gespach C, Estlein $\mathrm{D}$, et al. Evidence for the involvement of the Wnt 2 gene in human colorectal cancer. Oncogene 1996;12:153-8.

29. Peifer M, Polakis P. Wnt signaling in oncogenesis and embryogenesis, a look outside the nucleus [review] Science 2000;287:1606-9.

30. Kang YK, Kim WH, Lee HW, Lee HK, Kim YI. Mutation of p53 and K-ras, and loss of heterozygosity of APC in intrahepatic cholangiocarcinoma. Lab Invest 1999;79:477-83. 